\title{
Serum 25-Hydroxyvitamin D3 and BAFF Levels Are Associated with Disease Activity in Primary Sjogren's Syndrome
}

\author{
Sang Jin Lee, ${ }^{1,2}$ Hye Jin Oh, ${ }^{1}$ Byoong Yong Choi, ${ }^{3}$ Yu Jin Jang, ${ }^{2}$ \\ Joo Youn Lee, ${ }^{2}$ Jin Kyun Park, ${ }^{1,2}$ and Yeong Wook Song ${ }^{1,2}$ \\ ${ }^{1}$ Division of Rheumatology, Department of Internal Medicine, Seoul National University Hospital, Seoul, Republic of Korea
${ }^{2}$ Department of Molecular Medicine and Biopharmaceutical Sciences, Graduate School of Convergence Science and Technology,
and College of Medicine, Medical Research Center, Seoul National University, Seoul, Republic of Korea \\ ${ }^{3}$ Division of Rheumatology, Department of Internal Medicine, Seoul Medical Center, Seoul, Republic of Korea
}

Correspondence should be addressed to Yeong Wook Song; ysong@snu.ac.kr

Received 7 August 2016; Accepted 9 November 2016

Academic Editor: Alessandra Santos

Copyright (C) 2016 Sang Jin Lee et al. This is an open access article distributed under the Creative Commons Attribution License, which permits unrestricted use, distribution, and reproduction in any medium, provided the original work is properly cited.

\begin{abstract}
The study investigated the association between disease activity and serum 25-hydroxyvitamin D3 (25(OH)-D3), B cell activation of the tumor necrosis factor family (BAFF), or $\beta_{2}$ microglobulin in patients with primary Sjogren's syndrome (SS). Sixty-nine primary SS patients and 22 sicca control patients were included in the study. Disease activity was measured with EULAR Sjogren's syndrome disease activity index (ESSDAI). Serum levels of 25(OH)-D3 and $\beta_{2}$ microglobulin were measured by radioimmunoassay and BAFF was measured by an enzyme-linked immunosorbent assay. Serum levels of 25(OH)-D3 were significantly lower in SS patients compared to the sicca controls $(p=0.036)$. Serum levels of BAFF tended to be higher $(p=0.225)$ and those of $\beta_{2}$ microglobulin were significantly higher in patients with SS than in sicca controls $(p=0.023)$. In univariate regression analyses, ESSDAI was significantly associated with serum levels of $25(\mathrm{OH})-\mathrm{D} 3, \mathrm{BAFF}$, and $\beta_{2}$ microglobulin. After stepwise backward multivariate linear regression analyses including age and acute phase reactants, ESSDAI was associated with $25(\mathrm{OH})-\mathrm{D} 3(\beta=-0.042, p=0.015)$ and BAFF $(\beta=0.001, p=0.015)$ in SS patients. In SS patients, ESSDAI is negatively associated with serum levels of $25(\mathrm{OH})-\mathrm{D} 3$ and positively associated with BAFF.
\end{abstract}

\section{Introduction}

Sjogren's syndrome (SS) is a chronic autoimmune disease affecting the exocrine glands that manifests as sicca symptoms including dry eyes and dry mouth. SS often involves extraglandular organs including joints, liver, lung, brain, and kidney. The extraglandular manifestations are mediated in part by the overproduction of multiple autoantibodies that are often directed against nuclear antigens such as antinuclear antibody (ANA) and anti-Ro/La antibodies, which lead to hypergammaglobulinemia due to chronic polyclonal B cell activation [1]. Lymphocytes or autoantibodies lead to the inflammation of the target tissues directly or due to the formation of immune complexes. Chronic B cell activation plays an important role in the pathogenesis of SS [2]. Factors associated with B cell activation were reported to correlate with SS disease activity; these include serum levels of B cell activating factor belonging to the tumor necrosis factor family (BAFF) [3], $\beta_{2}$ microglobulin $[4,5]$, and free light chains of immunoglobulin [6].

Vitamin D3 has an immunomodulatory function [7]. Low serum vitamin D3 levels have been associated with several autoimmune diseases including multiple sclerosis, type 1 diabetes mellitus, rheumatoid arthritis (RA), systemic lupus erythematous (SLE), Behcet's disease (BD), and idiopathic inflammatory myopathies [8-13]. In RA and SLE patients, vitamin D3 levels negatively correlate with disease activity $[14,15]$. Data on vitamin D3 levels in SS have been conflicting. Some studies reported that vitamin D3 levels were similar between SS patients and healthy controls [16] and did not correlate with EULAR Sjogren's syndrome disease activity index (ESSDAI), but the number of enrolled SS patients was small $(n=30)$ [17]. Other studies showed that vitamin D3 levels were significantly lower in SS patients compared to 
healthy controls [18] and low levels of vitamin D3 were associated with the presence of peripheral neuropathy and lymphoma [19].

The aim of the present study was to investigate the association between SS disease activity and serum 25(OH)-D3, BAFF, and $\beta_{2}$ microglobulin.

\section{Material and Methods}

2.1. Study Population. Sixty-nine patients with primary SS according to the American-European Consensus Classification Criteria [20] and 22 age- and sex-matched patients with sicca as a control group were recruited from the Rheumatology Clinic of Seoul National University Hospital. Primary SS patients did not have any other autoimmune diseases and the control patients had dry mouth and/or dry eyes but were not diagnosed with SS. This study was performed between November 2012 and February 2013. The study protocol was approved by the Ethics Committee of Seoul National University Hospital. All patients gave informed consent.

2.2. Assessment of SS Activity and Serological Parameters. Clinical and laboratory data were obtained from medical records. Disease activity of SS expressed as ESSDAI was ascertained at the time of blood sampling [21]. Serum levels of $25(\mathrm{OH})-\mathrm{D} 3$ and $\beta_{2}$ microglobulin were measured by radioimmunoassay (RIA) (Immunotech, Sao Paulo, Brazil, and DiaSorin, Minneapolis, MN, USA, resp.). Serum levels of BAFF were determined by enzyme-linked immunosorbent assay (ELISA) (R\&D Systems, Minneapolis, MN, USA). Serum antinuclear antibody (ANA) was detected by indirect immunofluorescence (Bio-Rad, Hercules, CA, USA), antiRo/La antibodies were detected by ELISA (Zeus Scientific, Somerville, NJ, USA), and RF was detected by immunoturbidimetry (Roche, Mannheim, Germany).

2.3. Statistical Analyses. Data are expressed as mean \pm standard error of mean (SEM) for continuous variables and as percentages for categorical variables. The Student $t$-test was used to compare continuous variables and chi-square test or Fisher's exact test was used to compare categorical variables. Correlation between ESSDAI scores and levels of serological parameters was analyzed by Spearman's correlation. Multivariate analyses by the stepwise backward method were used to evaluate the association between serological parameters and ESSDAI. $p$ values $<0.05$ were considered statistically significant. All statistical analyses were performed using SPSS version 19 software (IBM, Chicago, IL, USA) and graphics were generated in GraphPad Prism version 5 (GraphPad, San Diego, CA, USA).

\section{Results}

3.1. Clinical and Laboratory Characteristics of Patients with SS and Sicca. Sixty-nine primary SS patients and 22 sicca patients were enrolled. The mean age $( \pm$ SEM) of the SS and sicca patients was $56.7 \pm 1.32$ and $58.0 \pm 2.66$ years, respectively. The majority of both groups were females $(98.6 \%$ in the SS group, $95.5 \%$ in the sicca group). The mean duration after diagnosis was $8.7 \pm 0.78$ and $5.7 \pm 1.09$ years, respectively.
Serum autoantibody positive rates were significantly higher in SS patients than in sicca patients: ANA $87.0 \%$ versus $13.6 \%$, anti-Ro (SSA) $91.3 \%$ versus $0.0 \%$, and anti-La (SSB) $62.3 \%$ versus $0.0 \%$ (all, $p<0.001$ ). The mean ESSDAI was $1.5 \pm 0.17$ in SS patients and none in sicca patients (Table 1). In SS, all patients took hydroxychloroquine. In addition, $36.2 \%(n=$ $25)$ and $17.4 \%(n=12)$ of patients received nonsteroidal anti-inflammatory drugs (NSAIDs) and low dose steroids (prednisolone equivalent $\leq 10 \mathrm{mg} /$ day), respectively.

3.2. Erythrocyte Sedimentation Rate (ESR) and Levels of Serum C-Reactive Protein (CRP), 25(OH)-D3, BAFF, and $\beta_{2}$ Microglobulin in SS and Sicca Patients. ESR $(26.6 \pm 2.50$ versus $11.5 \pm 1.64 \mathrm{~mm} / \mathrm{hr}$, respectively; $p<0.001)$ and $\beta_{2}$ microglobulin $(1.57 \pm 0.08$ versus $1.19 \pm 0.08 \mathrm{mg} / \mathrm{L}$, respectively; $p=0.023$ ) were significantly higher in SS patients compared to sicca patients. CRP levels were not significantly different in both groups $(0.24 \pm 0.06$ versus $0.13 \pm 0.10 \mathrm{mg} / \mathrm{dL}$, respectively; $p=0.368)$. $25(\mathrm{OH})-\mathrm{D} 3$ levels were significantly decreased in SS patients compared to sicca patients $(22.0 \pm$ 1.32 versus $28.0 \pm 2.69 \mathrm{ng} / \mathrm{mL}$, respectively; $p=0.036$ ). Levels of BAFF tended to be higher, albeit nonsignificant, in SS patients compared to sicca patients $(1543 \pm 141$ versus $1200 \pm$ $182 \mathrm{pg} / \mathrm{mL}$, respectively; $p=0.225$ ) (Table 1 ). There were no significant differences in levels of $25(\mathrm{OH})-\mathrm{D} 3, \mathrm{BAFF}$, and $\beta_{2}$ microglobulin according to medications (NSAIDs or steroids in patients with SS, data not shown).

Extraglandular involvement was present in 35 patients of SS $(50.7 \%)$. We analyzed age and serological parameters according to extraglandular organ involvement in SS patients. ESSDAI and levels of CRP and BAFF were significantly higher in the group of extraglandular involvement. But levels of 25(OH)-D3 tended to be lower in this group (see Supplementary Table 1 in Supplementary Material available online at http://dx.doi.org/10.1155/2016/5781070).

3.3. Correlation between ESSDAI Scores and Serological Parameters. ESSDAI tended to correlate with levels of ESR ( $r=$ $0.228, p=0.059)$ or CRP $(r=0.237, p=0.052)$. ESSDAI was inversely correlated with serum levels of $25(\mathrm{OH})-\mathrm{D} 3$ $(r=-0.444, p<0.001)$ (Figure 1). But levels of 25(OH)D3 were not significantly correlated with age, ESR, levels of CRP, BAFF, and $\beta_{2}$ microglobulin in SS patients (Table 2). There was a positive correlation between ESSDAI and levels of BAFF $(r=0.340, p=0.018)$ or $\beta_{2}$ microglobulin $(r=0.362, p=0.007)$ (Figure 1). Levels of BAFF were not significantly correlated with age, levels of CRP, 25(OH)-D3, and $\beta_{2}$ microglobulin, except ESR in SS patients. Levels of $\beta_{2}$ microglobulin were not significantly correlated with age, levels of 25(OH)-D3, and BAFF, except ESR and levels of CRP in SS patients (Table 2).

3.4. Associations of ESSDAI with Serological Parameters by Univariate and Multivariate Linear Regression. In univariate regression analyses, 25(OH)-D3, BAFF, and $\beta_{2}$ microglobulin were significantly associated with ESSDAI. To identify factors associated with ESSDAI, multivariate linear regression analyses were performed considering age, ESR, and CRP in addition to $25(\mathrm{OH})-\mathrm{D} 3, \mathrm{BAFF}$, and $\beta_{2}$ microglobulin. 


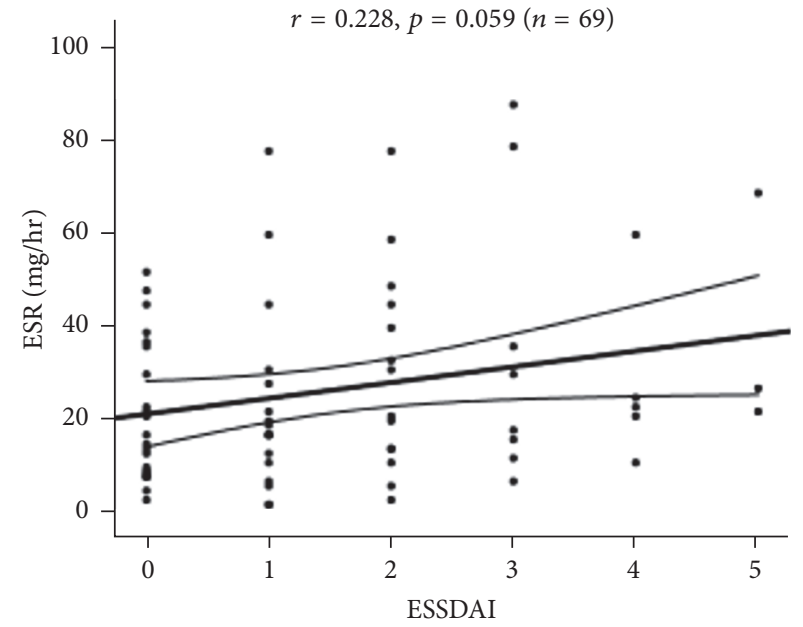

(a)

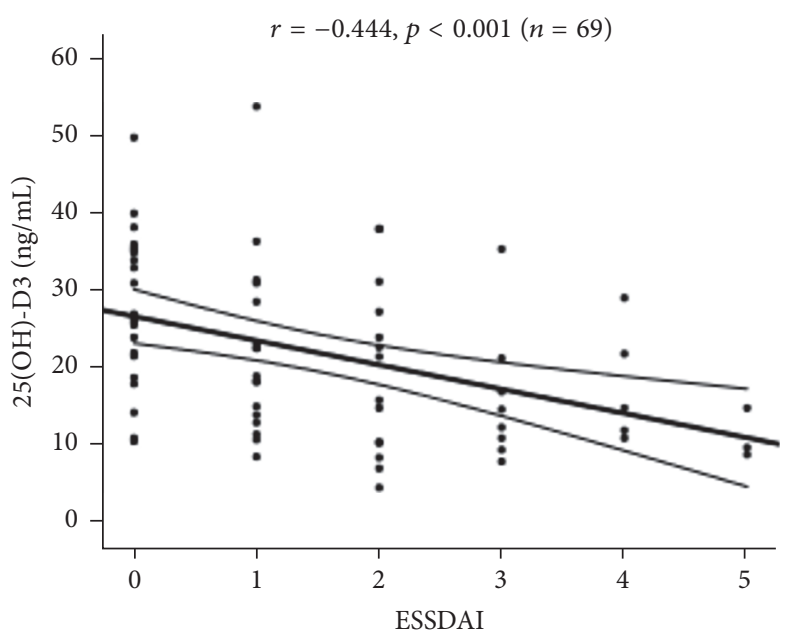

(c)

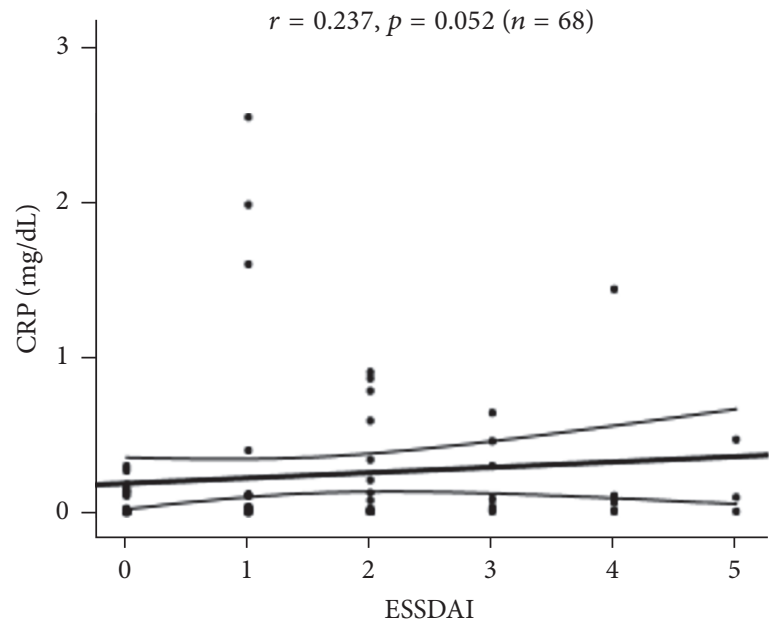

(b)

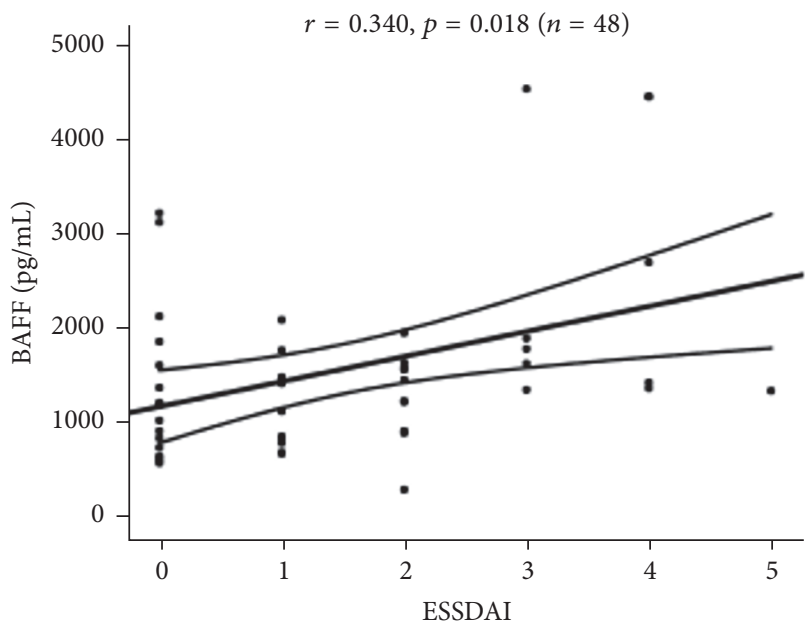

(d)

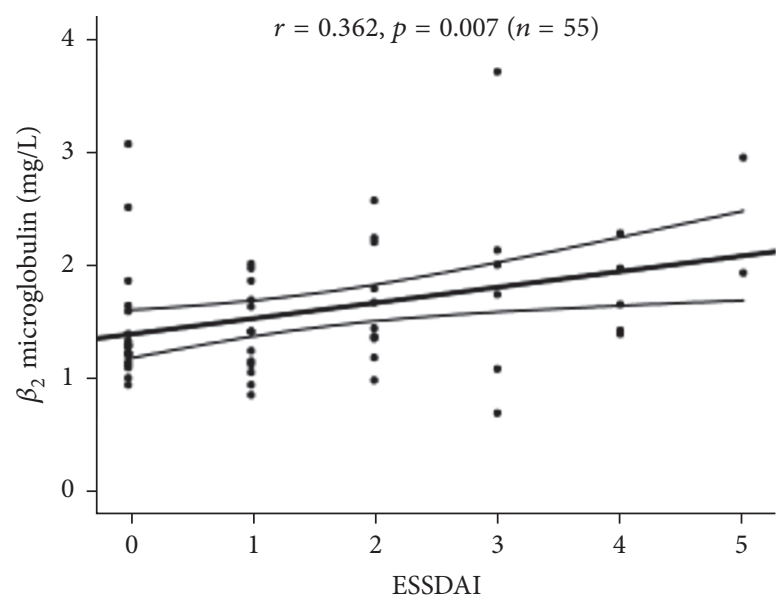

(e)

FIGURE 1: Correlation of ESSDAI with levels of ESR, serum CRP, 25(OH)-D3, BAFF, and $\beta_{2}$ microglobulin in patients with primary Sjogren's syndrome. Each dot represents individual value (correlation coefficient and $p$ value by Spearman's rank correlation test). 
TABLE 1: Clinical and laboratory characteristics of primary Sjogren's syndrome and sicca patients.

\begin{tabular}{|c|c|c|c|}
\hline Features & Sjogren's syndrome $(n=69)$ & Sicca $(n=22)$ & $p$ value \\
\hline Age at diagnosis, years & $56.7 \pm 1.32$ & $58.0 \pm 2.66$ & 0.651 \\
\hline Sex, female (\%) & $68(98.6)$ & $21(95.5)$ & 0.427 \\
\hline BMI $\left(\mathrm{kg} / \mathrm{m}^{2}\right)$ & $21.9 \pm 0.34$ & $22.5 \pm 0.63$ & 0.356 \\
\hline Disease duration, years & $8.7 \pm 0.78$ & $5.7 \pm 1.09$ & $0.047^{*}$ \\
\hline Anti-Ro (SSA), $n(\%)$ & $63(91.3)$ & $0(0.0)$ & $<0.001^{*}$ \\
\hline Anti-La (SSB), $n(\%)$ & $43(62.3)$ & $0(0.0)$ & $<0.001^{*}$ \\
\hline Antinuclear antibody, $n(\%)$ & $60(87.0)$ & $3(13.6)$ & $<0.001^{*}$ \\
\hline Rheumatoid factor, $n(\%)$ & $37 / 64(57.8)$ & $7(31.8)$ & $0.043^{*}$ \\
\hline $\operatorname{ESR}(\mathrm{mm} / \mathrm{hr})$ & $26.6 \pm 2.50$ & $11.5 \pm 1.64$ & $<0.001^{*}$ \\
\hline CRP (mg/dL) & $0.24 \pm 0.06$ & $0.13 \pm 0.10$ & 0.365 \\
\hline 25(OH)-D3 (ng/mL) & $22.0 \pm 1.32$ & $28.0 \pm 2.69$ & $0.036^{*}$ \\
\hline BAFF $(\mathrm{pg} / \mathrm{mL})$ & $1543 \pm 141$ & $1200 \pm 182$ & 0.225 \\
\hline$\beta_{2}$ microglobulin $(\mathrm{mg} / \mathrm{L})$ & $1.57 \pm 0.08$ & $1.19 \pm 0.08$ & $0.023^{*}$ \\
\hline Extraglandular involvement (\%) & $35(50.7)$ & 0 & \\
\hline ESSDAI & $1.5 \pm 0.17$ & 0 & \\
\hline
\end{tabular}

Data are presented as mean \pm SEM for continuous data and number (percentage) for categorical variables. BMI $=$ body mass index; ESR $=$ erythrocyte sedimentation rate; $\mathrm{CRP}=\mathrm{C}$-reactive protein; $\mathrm{BAFF}=\mathrm{B}$ cell activation of the TNF family; ESSDAI = EULAR Sjogren's syndrome disease activity index; ${ }^{*} p<0.05$.

TABLE 2: Correlations between serum levels of 25(OH)-D3, BAFF, or $\beta_{2}$ microglobulin and serological parameters were evaluated in primary Sjogren's syndrome.

\begin{tabular}{lccccc}
\hline & $\begin{array}{c}25(\mathrm{OH})-\mathrm{D} 3 \\
\text { Correlation efficient }\end{array}$ & $p$ value & Correlation efficient & $p$ value & $\begin{array}{c}\beta_{2} \text { microglobulin } \\
\text { Correlation efficient }\end{array}$ \\
\hline Age & -0.110 & 0.366 & 0.101 & 0.493 & 0.233 \\
ESR & 0.174 & 0.153 & 0.311 & $0.031^{*}$ & 0.498 \\
CRP & -0.009 & 0.941 & 0.281 & 0.055 & 0.086 \\
$25(\mathrm{OH})$-D3 & & & -0.028 & 0.849 & -0.096 \\
BAFF & -0.028 & 0.849 & & & $0.030^{*}$ \\
$\beta_{2}$ microglobulin & -0.096 & 0.485 & 0.215 & 0.147 & 0.485 \\
\hline
\end{tabular}

Correlation coefficient and $p$ value were analyzed by Spearman's rank correlation test. ESR = erythrocyte sedimentation rate; $\mathrm{CRP}=\mathrm{C}$-reactive protein; $\mathrm{BAFF}=$ B cell activation of the TNF family; ${ }^{*} p<0.05$.

ESSDAI was associated with $25(\mathrm{OH})-\mathrm{D} 3(\beta=-0.042, p=$ $0.015)$ and $\operatorname{BAFF}(\beta=0.001, p=0.015)$, but not with age $(\beta=-0.036, p=0.076)$ (Table 3).

\section{Discussion}

In the present study, serum levels of $25(\mathrm{OH})$-D3 were significantly lower and those of $\beta_{2}$ microglobulin were significantly higher in patients with SS compared with age- and sexmatched sicca controls. Levels of BAFF tended to be higher in SS patients. Consistent with previous reports $[3,5]$, our data showed that ESSDAI was correlated with serum beta2microglobulin in SS patients in univariate analyses. But in multivariate analyses including serum levels of 25(OH)-D3, BAFF, and $\beta_{2}$ microglobulin, ESSDAI was associated with $25(\mathrm{OH})-\mathrm{D} 3$ and BAFF but not with $\beta_{2}$ microglobulin. These suggest that both serum levels of $25(\mathrm{OH})-\mathrm{D} 3$ and BAFF are independent predictors of ESSDAI in SS patients.

There is limitation in this study. Disease activity of enrolled patients was relatively low. Larger studies of SS patients with higher disease activity may be needed for further validation.

BAFF enhances $B$ cell maturation, proliferation, and survival [1]. Serum levels of BAFF are increased in patients with autoimmune diseases such as SLE, SS, and rheumatoid arthritis [22]. It was reported that elevated serum BAFF levels were independent predictor of flare in patients who were receiving standard SLE therapy [23]. BAFF upregulation was associated with B cell clonal expansion in the salivary gland and correlated with SS disease activity $[3,4]$. Long-term treatment with belimumab, a fully human monoclonal antibody direct against BAFF, decreased disease activity and was safe in both SLE and SS patients $[24,25]$. $\beta_{2}$ microglobulin forms the light chain of MHC class I molecules that are crucial for antigen presentation to $\mathrm{T}$ cell receptor. Serum levels of $\beta_{2}$ microglobulin were associated with extraglandular involvement such as renal or pulmonary manifestations in patients with SS [26, 27].

Low levels of $25(\mathrm{OH})-\mathrm{D} 3$ have been associated with lymphoma and observed in SS patients over 66 years of age 
TABLE 3: Associations of ESSDAI with serological parameters by univariate and multivariate linear regression.

\begin{tabular}{|c|c|c|c|c|}
\hline \multirow{2}{*}{ Variate } & \multicolumn{2}{|c|}{ Univariate analyses } & \multicolumn{2}{|c|}{ Multivariate analyses (backward stepwise) } \\
\hline & $\beta \pm \mathrm{SE}$ & $p$ value & $\beta \pm \mathrm{SE}$ & $p$ value \\
\hline Age (years) & $-0.006 \pm 0.016$ & 0.732 & $-0.036 \pm 0.020$ & 0.076 \\
\hline $\operatorname{ESR}(\mathrm{mm} / \mathrm{hr})$ & $0.017 \pm 0.008$ & 0.050 & & \\
\hline $\mathrm{CRP}(\mathrm{mg} / \mathrm{dL})$ & $0.320 \pm 0.374$ & 0.396 & & \\
\hline 25(OH)-D3 (ng/mL) & $-0.055 \pm 0.015$ & $<0.001^{*}$ & $-0.042 \pm 0.016$ & $0.015^{*}$ \\
\hline $\mathrm{BAFF}(\mathrm{pg} / \mathrm{mL})$ & $0.001 \pm 0.000$ & $0.007^{*}$ & $0.001 \pm 0.000$ & $0.015^{*}$ \\
\hline$\beta_{2}$ microglobulin $(\mathrm{mg} / \mathrm{L})$ & $0.865 \pm 0.321$ & $0.009^{*}$ & & \\
\hline
\end{tabular}

ESSDAI = EULAR Sjogren's syndrome disease activity index; ESR $=$ erythrocyte sedimentation rate; $\mathrm{CRP}=\mathrm{C}$-reactive protein; $\mathrm{BAFF}=\mathrm{B}$ cell activation of the TNF family; ${ }^{*} p<0.05$.

compared to patients below 50 years of age [19]. There were no patients with lymphoma enrolled in our study and SS patients $>66$ years of age tended to have lower levels of $25(\mathrm{OH})-\mathrm{D} 3$ than those $<50$ years of age $(19.27 \pm 2.44$ versus $24.06 \pm 2.81$; $p=0.285)$. However, when we used multivariate linear regression analyses including age, ESSDAI was associated with $25(\mathrm{OH})$-D3 but not with age.

Vitamin D may play an immunomodulatory role in both innate and adaptive immunity [28]. 1,25(OH)2D3 suppresses Toll-like receptor- (TLR-) 2 and TLR- 4 expression in human monocytes, leading to hyporesponsiveness to pathogenassociated molecular patterns $[29,30]$. Specifically, this hormone inhibits TLR-2 and TLR-4 expression of monocytes in $\mathrm{BD}$ patients in a dose-dependent manner [31]. 1,25(OH)2D3 promotes a shift in the Thelper (Th)1/Th2 balance toward Th2 and downregulates Th17 autoimmunity by reducing interleukin-17A-secreting CD4+ T cells [32, 33]. A highly significant negative correlation between levels of $25(\mathrm{OH})$ D3 and IgG levels in healthy female was reported [34]. In addition 1,25(OH)2D3 level was associated with reduced human B cell proliferation, plasma cell differentiation, and IgG production from peripheral blood in vitro [35]. Activation of B cells is crucial and the risk of lymphoma is increased in SS compared to the general population [1, 2]. B cell targeted agents, such as rituximab and belimumab, significantly improved ESSDAI compared to placebo treatment in SS patients [36]. Our results suggest that low levels of $25(\mathrm{OH})$-D3 are associated with increased systemic disease activity in SS patients.

Low vitamin $\mathrm{D}$ levels were associated with many rheumatic diseases such as RA, SLE, BD, and idiopathic inflammatory myopathies [10-13]. Recently, systematic review and meta-analysis have highlighted associations between vitamin $\mathrm{D}$ deficiency and ankylosing spondylitis and inflammatory bowel disease $[37,38]$.

Long-term administration of vitamin D3 analogs in mice decreases the levels of serum IgG and interleukin2 , which are crucial in the immune system [39]. Vitamin $\mathrm{D}$ deficiency is common in patients with rheumatic disease particularly SLE [40]. After vitamin D supplementation modest improvement of disease activity [41, 42] and restoration of B cell homeostasis were observed in SLE [43]. However other studies showed that vitamin D supplementation failed to affect disease activity and diminish the interferon signature in patients with SLE $[44,45]$. Additionally, replacement of vitamin D improved endothelial function in BD patients [46]. Supplementation of vitamin D may be considered in patients with SS and lower vitamin D levels.

\section{Conclusions}

Serum levels of 25(OH)-D3 were significantly lower in patients with SS compared with age- and sex-matched sicca controls. ESSDAI is negatively associated with serum levels of 25(OH)-D3 and positively associated with BAFF in patients with SS.

\section{Competing Interests}

The authors declare no conflict of interests.

\section{Authors' Contributions}

All authors were involved in data collection and analysis, critical revision, and final approval of the manuscript. Sang Jin Lee, Hye Jin Oh, and Yeong Wook Song were involved in study conception and design and writing. Acquisition of data was done by Byoong Yong Choi, Yu Jin Jang, Joo Youn Lee, and Jin Kyun Park. Sang Jin Lee and Hye Jin Oh contributed equally to this work.

\section{Acknowledgments}

This study was supported by a grant of the Korea Health Technology R\&D Project through the Korea Health Industry Development Institute (KHIDI), funded by the Ministry of Health \& Welfare, Republic of Korea (Grant no. HI14C1277).

\section{References}

[1] G. Nocturne and X. Mariette, "Advances in understanding the pathogenesis of primary Sjögren's syndrome," Nature Reviews Rheumatology, vol. 9, no. 9, pp. 544-556, 2013.

[2] X. Mariette and J.-E. Gottenberg, "Pathogenesis of Sjögren's syndrome and therapeutic consequences," Current Opinion in Rheumatology, vol. 22, no. 5, pp. 471-477, 2010.

[3] L. Quartuccio, S. Salvin, M. Fabris et al., "BLyS upregulation in Sjogren's syndrome associated with lymphoproliferative disorders, higher ESSDAI score and B-cell clonal expansion in the salivary glands," Rheumatology, vol. 52, no. 2, pp. 276-281, 2013. 
[4] J.-E. Gottenberg, M. Busson, J. Cohen-Solal et al., "Correlation of serum B lymphocyte stimulator and $\beta 2$ microglobulin with autoantibody secretion and systemic involvement in primary Sjögren's syndrome," Annals of the Rheumatic Diseases, vol. 64, no. 7, pp. 1050-1055, 2005.

[5] M. Pertovaara and M. Korpela, "Serum $\beta 2$ microglobulin correlates with the new ESSDAI in patients with Sjögren's syndrome," Annals of the Rheumatic Diseases, vol. 70, no. 12, pp. 2236-2237, 2011.

[6] J.-E. Gottenberg, R. Seror, C. Miceli-Richard et al., "Serum levels of beta2-microglobulin and free light chains of immunoglobulins are associated with systemic disease activity in primary sjögren's syndrome. Data at enrollment in the prospective ASSESS cohort," PLOS ONE, vol. 8, no. 5, Article ID e59868, 2013.

[7] J. R. Mora, M. Iwata, and U. H. von Andrian, "Vitamin effects on the immune system: vitamins A and D take centre stage," Nature Reviews Immunology, vol. 8, no. 9, pp. 685-698, 2008.

[8] M. Bäärnhielm, A. K. Hedström, I. Kockum et al., "Sunlight is associated with decreased multiple sclerosis risk: no interaction with human leukocyte antigen-DRB1 ${ }^{\star} 15$," European Journal of Neurology, vol. 19, no. 7, pp. 955-962, 2012.

[9] M. Cutolo, M. Plebani, Y. Shoenfeld, L. Adorini, and A. Tincani, "Vitamin D endocrine system and the immune response in rheumatic diseases," Vitamins and Hormones, vol. 86, pp. 327351, 2011.

[10] Q. Hong, J. Xu, S. Xu, L. Lian, M. Zhang, and C. Ding, "Associations between serum 25-hydroxyvitamin D and disease activity, inflammatory cytokines and bone loss in patients with rheumatoid arthritis," Rheumatology, vol. 53, no. 11, pp. 19942001, 2014.

[11] D. L. Kamen, G. S. Cooper, H. Bouali, S. R. Shaftman, B. W. Hollis, and G. S. Gilkeson, "Vitamin D deficiency in systemic lupus erythematosus," Autoimmunity Reviews, vol. 5, no. 2, pp. 114-117, 2006.

[12] K. Hamzaoui, I. B. Dhifallah, E. Karray, F. H. Sassi, and A. Hamzaoui, "Vitamin D modulates peripheral immunity in patients with Behçet's disease," Clinical and Experimental Rheumatology, vol. 28, no. 4, pp. S50-S57, 2010.

[13] P. Azali, S. B. Helmers, I. Kockum et al., "Low serum levels of vitamin D in idiopathic inflammatory myopathies," Annals of the Rheumatic Diseases, vol. 72, no. 4, pp. 512-516, 2013.

[14] M. Cutolo, K. Otsa, K. Laas et al., "Circannual vitamin d serum levels and disease activity in rheumatoid arthritis: northern versus Southern Europe," Clinical and Experimental Rheumatology, vol. 24, no. 6, pp. 702-704, 2006.

[15] C. C. Mok, D. J. Birmingham, L. Y. Ho, L. A. Hebert, H. Song, and B. H. Rovin, "Vitamin D deficiency as marker for disease activity and damage in systemic lupus erythematosus: a comparison with anti-dsDNA and anti-Clq," Lupus, vol. 21, no. 1, pp. 36-42, 2012.

[16] P. Szodoray, I. F. Horvath, G. Papp et al., "The immunoregulatory role of vitamins $\mathrm{A}, \mathrm{D}$ and $\mathrm{E}$ in patients with primary Sjögren's syndrome," Rheumatology, vol. 49, no. 2, pp. 211-217, 2010.

[17] C. Baldini, A. Delle Sedie, N. Luciano et al., "Vitamin D in 'early' primary Sjögren's syndrome: does it play a role in influencing disease phenotypes?" Rheumatology International, vol. 34, no. 8, pp. 1159-1164, 2014.

[18] Ş. Erten, A. Şahin, A. Altunoğlu, E. Gemcioğlu, and C. Koca, "Comparison of plasma vitamin D levels in patients with
Sjögren's syndrome and healthy subjects," International Journal of Rheumatic Diseases, vol. 18, no. 1, pp. 70-75, 2015.

[19] N. Agmon-Levin, S. Kivity, A. G. Tzioufas et al., "Low levels of vitamin-D are associated with neuropathy and lymphoma among patients with Sjögren's syndrome," Journal of Autoimmunity, vol. 39, no. 3, pp. 234-239, 2012.

[20] C. Vitali, S. Bombardieri, R. Jonsson et al., "Classification criteria for Sjögren's syndrome: A revised version of the European criteria proposed by the American-European Consensus Group," Annals of the Rheumatic Diseases, vol. 61, no. 6, pp. 554558, 2002.

[21] R. Seror, P. Ravaud, S. J. Bowman et al., "EULAR Sjögren's syndrome disease activity index: development of a consensus systemic disease activity index for primary Sjögren's syndrome," Annals of the Rheumatic Diseases, vol. 69, no. 6, pp. 1103-1109, 2010.

[22] F. B. Vincent, D. Saulep-Easton, W. A. Figgett, K. A. Fairfax, and F. Mackay, "The BAFF/APRIL system: emerging functions beyond B cell biology and autoimmunity," Cytokine and Growth Factor Reviews, vol. 24, no. 3, pp. 203-215, 2013.

[23] M. A. Petri, R. F. van Vollenhoven, J. Buyon et al., "Baseline predictors of systemic lupus erythematosus flares: data from the combined placebo groups in the phase III belimumab trials," Arthritis \& Rheumatism, vol. 65, no. 8, pp. 2143-2153, 2013.

[24] L. Iaccarino, S. Bettio, R. Reggia et al., "Effects of belimumab on flare rate and expected damage progression in patients with active systemic lupus erythematosus," Arthritis Care \& Research, 2016.

[25] S. D. Vita, L. Quartuccio, R. Seror et al., "Efficacy and safety of belimumab given for 12 months in primary Sjögren's syndrome: the BELISS open-label phase II study," Rheumatology, vol. 54, no. 12, pp. 2249-2256, 2016.

[26] M. Pertovaara, M. Korpela, T. Kouri, and A. Pasternack, “The occurrence of renal involvement in primary Sjogren's syndrome: a study of 78 patients," Rheumatology, vol. 38, no. 11, pp. 1113-1120, 1999.

[27] M. Pertovaara, M. Korpela, S. Saarelainen et al., "Long-term follow-up study of pulmonary findings in patients with primary Sjögren's syndrome," Scandinavian Journal of Rheumatology, vol. 33, no. 5, pp. 343-348, 2004.

[28] M. Di Rosa, M. Malaguarnera, F. Nicoletti, and L. Malaguarnera, "Vitamin D3: a helpful immuno-modulator," Immunology, vol. 134, no. 2, pp. 123-139, 2011.

[29] K. Sadeghi, B. Wessner, U. Laggner et al., "Vitamin D3 downregulates monocyte TLR expression and triggers hyporesponsiveness to pathogen-associated molecular patterns," European Journal of Immunology, vol. 36, no. 2, pp. 361-370, 2006.

[30] M. Di Rosa, G. Malaguarnera, C. De Gregorio, M. Palumbo, G. Nunnari, and L. Malaguarnera, "Immuno-modulatory effects of vitamin D3 in human monocyte and macrophages," Cellular Immunology, vol. 280, no. 1, pp. 36-43, 2012.

[31] J. E. Do, S. Y. Kwon, S. Park, and E.-S. Lee, "Effects of vitamin D on expression of Toll-like receptors of monocytes from patients with Behçet's disease," Rheumatology, vol. 47, no. 6, pp. 840-848, 2008.

[32] E. Peelen, S. Knippenberg, A.-H. Muris et al., "Effects of vitamin $\mathrm{D}$ on the peripheral adaptive immune system: a review," Autoimmunity Reviews, vol. 10, no. 12, pp. 733-743, 2011.

[33] S. Joshi, L.-C. Pantalena, X. K. Liu et al., "1,25-Dihydroxyvitamin $\mathrm{D}_{3}$ ameliorates Th17 autoimmunity via transcriptional modulation of interleukin-17A," Molecular and Cellular Biology, vol. 31, no. 17, pp. 3653-3669, 2011. 
[34] F. R. Pérez-López, "Vitamin D and its implications for musculoskeletal health in women: an update," Maturitas, vol. 58, no. 2 , pp. 117-137, 2007.

[35] S. Chen, G. P. Sims, X. C. Xiao, Y. G. Yue, S. Chen, and P. E. Lipsky, "Modulatory effects of 1,25-dihydroxyvitamin D3 on human B cell differentiation," Journal of Immunology, vol. 179, no. 3, pp. 1634-1647, 2007.

[36] P. R. U. Sada, D. Isenberg, and C. Ciurtin, "Biologic treatment in Sjögren's syndrome," Rheumatology, vol. 54, no. 2, pp. 219-230, 2015.

[37] S. Zhao, S. J. Duffield, R. J. Moots, and N. J. Goodson, "Systematic review of association between vitamin $\mathrm{D}$ levels and susceptibility and disease activity of ankylosing spondylitis," Rheumatology (Oxford), vol. 53, no. 9, pp. 1595-1603, 2014.

[38] R. Del Pinto, D. Pietropaoli, A. K. Chandar, C. Ferri, and F. Cominelli, "Association between inflammatory bowel disease and vitamin D deficiency: a systematic review and metaanalysis," Inflammatory Bowel Diseases, vol. 21, no. 11, pp. 27082717, 2015.

[39] E. A. Smith, E. P. Frankenburg, S. A. Goldstein et al., "Effects of long-term administration of vitamin D3 analogs to mice," Journal of Endocrinology, vol. 165, no. 1, pp. 163-172, 2000.

[40] N. Agmon-Levin, E. Theodor, R. M. Segal, and Y. Shoenfeld, "Vitamin D in systemic and organ-specific autoimmune diseases," Clinical Reviews in Allergy and Immunology, vol. 45, no. 2, pp. 256-266, 2013.

[41] A. Abou-Raya, S. Abou-Raya, and M. Helmii, "The effect of vitamin $\mathrm{D}$ supplementation on inflammatory and hemostatic markers and disease activity in patients with systemic lupus erythematosus: a randomized placebo-controlled trial," Journal of Rheumatology, vol. 40, no. 3, pp. 265-272, 2013.

[42] M. Petri, K. J. Bello, H. Fang, and L. S. Magder, "Vitamin D in systemic lupus erythematosus: modest association with disease activity and the urine protein-to-creatinine ratio," Arthritis and Rheumatism, vol. 65, no. 7, pp. 1865-1871, 2013.

[43] B. Terrier, N. Derian, Y. Schoindre et al., "Restoration of regulatory and effector $\mathrm{T}$ cell balance and $\mathrm{B}$ cell homeostasis in systemic lupus erythematosus patients through vitamin D supplementation," Arthritis Research and Therapy, vol. 14, no. 5, article no. R221, 2012.

[44] L. Andreoli, F. Dall'Ara, S. Piantoni et al., "A 24-month prospective study on the efficacy and safety of two different monthly regimens of vitamin D supplementation in pre-menopausal women with systemic lupus erythematosus," Lupus, vol. 24, no. 4-5, pp. 499-506, 2015.

[45] C. Aranow, D. L. Kamen, M. Dall'Era et al., "Randomized, double-blind, placebo-controlled trial of the effect of vitamin $\mathrm{D}_{3}$ on the interferon signature in patients with systemic lupus erythematosus," Arthritis and Rheumatology, vol. 67, no. 7, pp. 1848-1857, 2015.

[46] M. Can, M. Gunes, O. A. Haliloglu et al., "Effect of vitamin D deficiency and replacement on endothelial functions in Behçet's disease," Clinical and Experimental Rheumatology, vol. 30, no. 3, supplement 72, pp. S57-S61, 2012. 


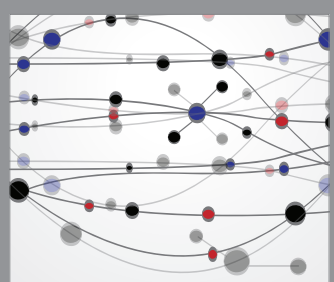

The Scientific World Journal
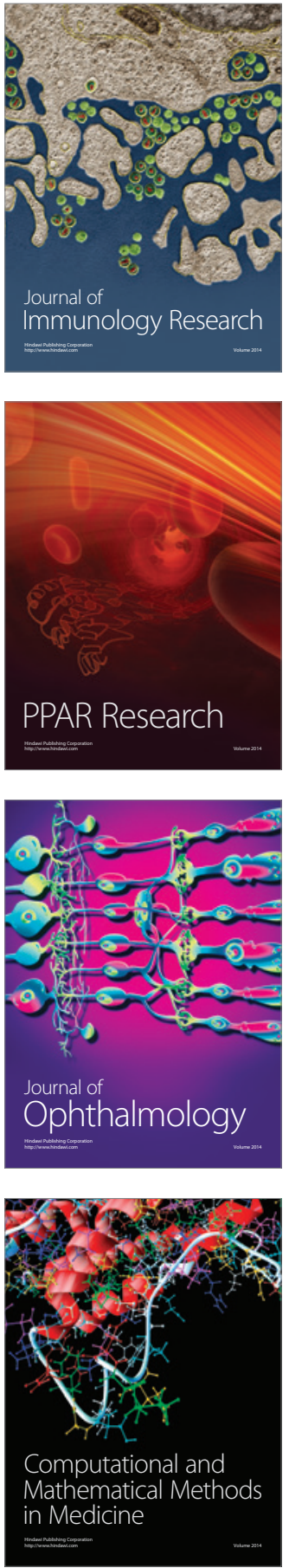

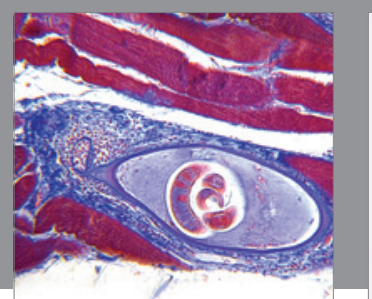

Gastroenterology Research and Practice

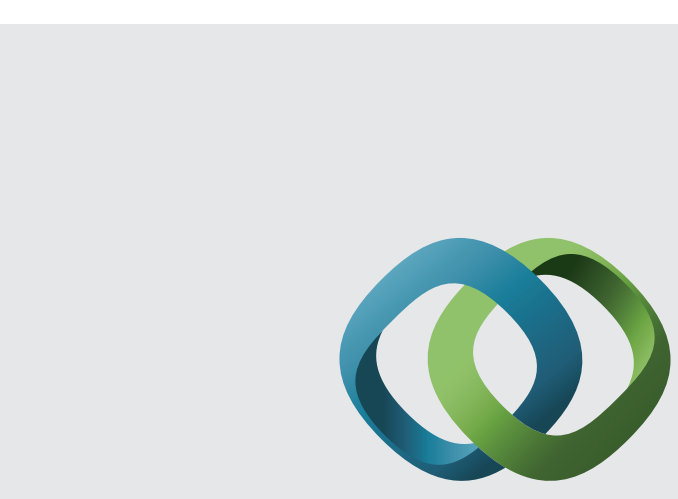

\section{Hindawi}

Submit your manuscripts at

http://www.hindawi.com
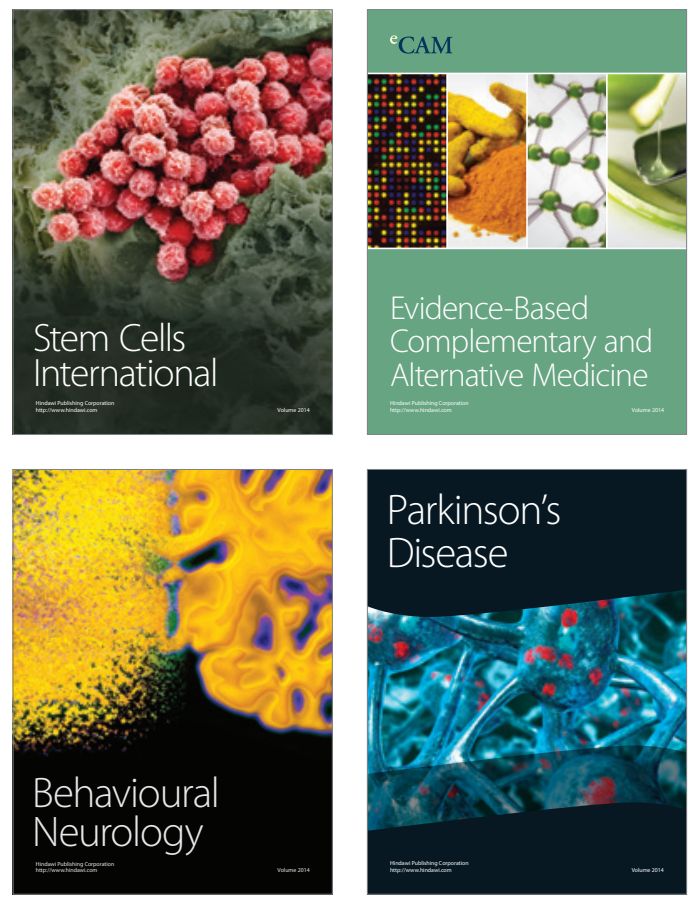
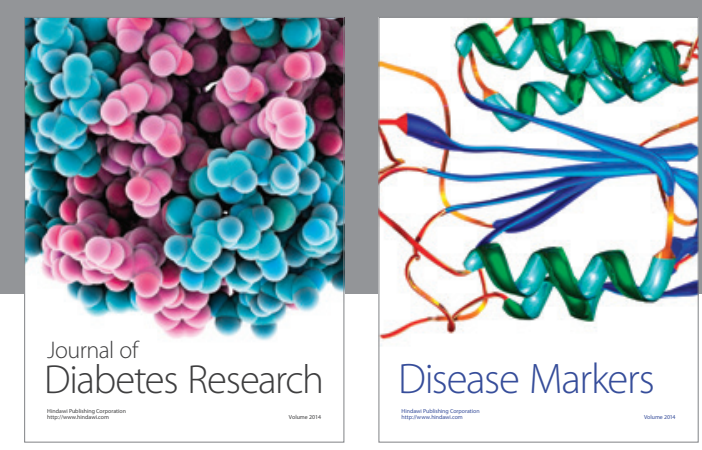

Disease Markers
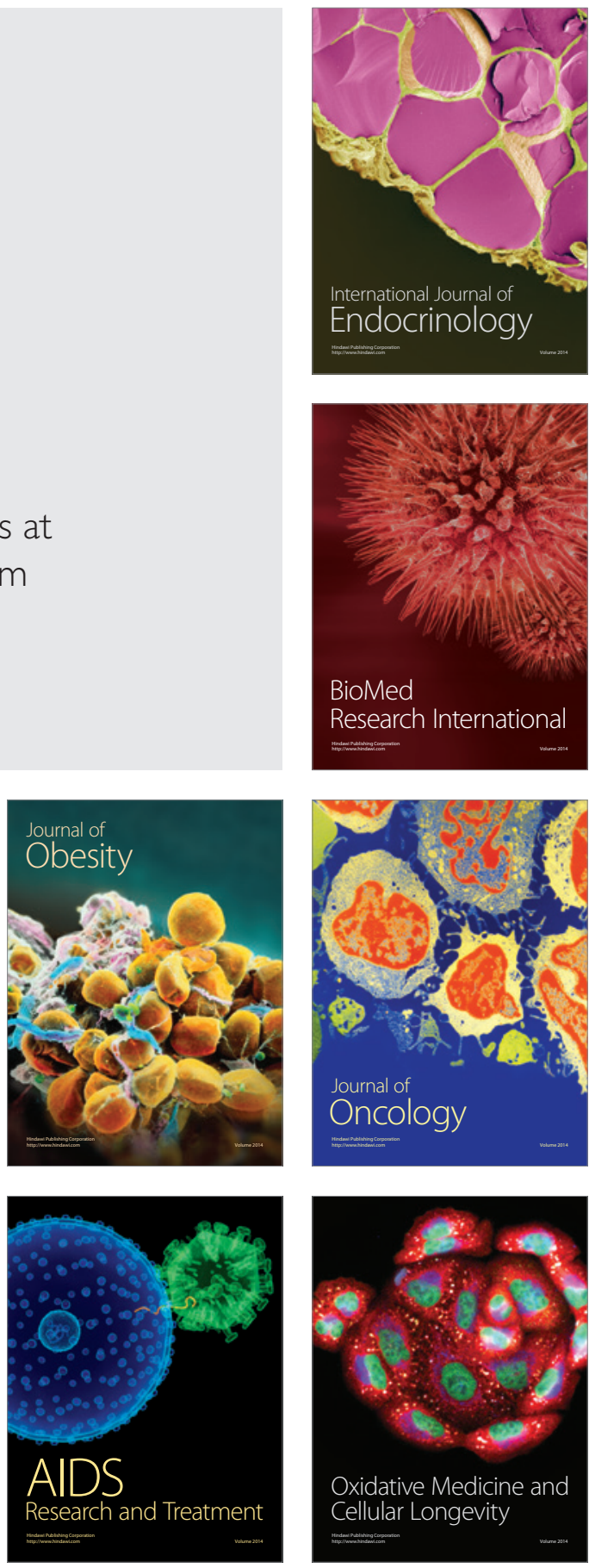